DOI: $10.17516 / 1998-2836-0273$

УДК 541.49: 546.92: 539.26

\title{
Preparation of a New Drug Based \\ on Cis-Dichlorodiamminplatin(II), Arabinogalactan and Aptamer AS-42 and Study of its Biological Activity
}

\author{
Alexander K. Starkov*a, \\ Sergey D. Kirik ${ }^{\mathrm{a}, \mathrm{b}}$, Tatyana N. Zamay ${ }^{\mathrm{c}}$, \\ Galina A. Kozuchovskaya ${ }^{a}$ and Anatoliy I. Rubaylo ${ }^{a}$ \\ anstitute of Chemistry and Chemical Technology SB RAS \\ FRC «Krasnoyarsk Science Center SB RAS» \\ Krasnoyarsk, Russian Federation \\ ${ }^{b}$ Siberian Federal University \\ Krasnoyarsk, Russian Federation \\ ${ }^{c}$ Krasnoyarsk State Medical University \\ named after Prof. V. F. Voino-Yasenetsky \\ Krasnoyarsk, Russian Federation
}

\begin{abstract}
A new drug based on a complex of cis-dichlorodiamminplatin(II) with arabinogalactan and aptamer AS-42 was obtained. The drug is characterized by the methods of XRD, thermogravimetry. IR spectroscopy. Its biological activity has been studied.
\end{abstract}

Keywords: platinum complex compound, synthesis, physico-chemical properties, arabinogalactan, aptamers.

Acknowledgements. The work was carried out within the framework of the state task of the Institute of Chemistry and Chemical Technology of the Siberian Branch of the Russian Academy of Sciences (project 0287-2021-0012).

Citation: Starkov, A. K., Kirik, S. D., Zamay, T. N., Kozuchovskaya, G. A., Rubaylo, A. I. Preparation of a new drug based on cis-dichlorodiamminplatin(II), arabinogalactan and aptamer AS-42 and study of its biological activity. J. Sib. Fed. Univ. Chem., 2022, 15(1), 81-89. DOI: 10.17516/1998-2836-0273

(C) Siberian Federal University. All rights reserved

This work is licensed under a Creative Commons Attribution-NonCommercial 4.0 International License (CC BY-NC 4.0)

* Corresponding author E-mail address: kaz@icct.ru 


\title{
Получение нового препарата
}

\section{на основе цис-дихлородиамминплатины(II), арабиногалактана и аптамера AS-42 \\ и изучение его биологической активности}

\author{
А.К. Старков ${ }^{\mathrm{a}}$, С. Д. Кирик ${ }^{\mathrm{a}, \boldsymbol{\sigma}}$, \\ Т.Н. Замай ${ }^{\text {, }, ~ Г . А . ~ К о ж у х о в с к а я ~}{ }^{\text {a }}$ А.И. Рубайло \\ ${ }^{a}$ Институт химии и химической технологии СО РАН \\ ФИЦ «Красноярский научный иентр СО РАН» \\ Российская Федерачия, Красноярск \\ ${ }^{6}$ Сибирский федеральный университет \\ Российская Федерачия, Красноярск \\ ${ }^{6}$ Красноярский государственный медицинский университет \\ им. проф.В.Ф. Войно-Ясенеикого \\ Российская Федерация, Красноярск
}

Аннотация. Получен новый препарат на основе комплекса цис-дихлородиамминплатины(II) с арабиногалактаном и аптамером AS-42. Препарат охарактеризован методами РФА, СТА и ИК-спектроскопии. Изучена его биологическая активность.

Ключевые слова: комплексное соединение платины, синтез, физико-химические свойства, арабиногалактан, аптамеры.

Благодарности. Работа выполнена в рамках государственного задания Института химии и химической технологии СО РАН (проект 0287-2021-0012).

Цитирование: Старков, А.К. Получение нового препарата на основе цис-дихлородиамминплатины(II), арабиногалактана и аптамераAS-42 и изучение его биологической активности / А. К. Старков, С.Д. Кирик, Т. Н. Замай, Г.А. Кожуховская, А. И. Рубайло // Журн. Сиб. федер. ун-та. Химия, 2022, 15(1). С. 81-89. DOI: 10.17516/1998-2836-0273

\section{Введение}

Анализ литературных данных по получению и свойствам препаратов на основе взаимодействия комплексов платины с арабиногалактаном показал, что данные по исследованию в этом направлении отсутствуют. Ранее полученный препарат при взаимодействии цисдихлородиамминплатины(II) с арабиногалактаном по способу [1] был идентифицирован [2] и исследован на биологическую активность [3]. Синтез проводили при нагревании. В качестве лиганда использовали сертифицированный арабиногалактан (Фибролар С), содержащий не более 1,5 \% флавоноидов [4]. Проведенные физико-химические исследования полученного препарата не позволили однозначно судить о составе и строении в связи с малым содержанием в нем комплекса платины (1,3\% по платине). 
Исследование его на биологическую активность показало, что он проявляет активность к асцитной карциноме Эрлиха и снижает токсичность, по сравнению с цисдихлородиамминплатины(II). Поэтому данное направление является новым и перспективным при разработке новых способов и методов получения препаратов на основе взаимодействия комплексов платины с арабиногалактаном.

Цель исследования - получение нового препарата на основе реакции цисдихлородиамминплатины(II) с арабиногалактаном, который будет обладать высокой биологической активностью и отсутствием токсичности. Необходимо установить его состав и строение.

В данной статье приводятся результаты синтеза нового препарата на основе взаимодействия цис-дихлородиамминплатины(II) с арабиногалактаном, а также результаты его физикохимического исследования. Изучена его биологическая активность.

\section{Материалы и методы}

Цис-дихлородиамминплатины(II) получен по способам [5, 6]. Для повышения чистоты микрокристаллической соли цис-дихлородиамминплатины(II) ее подвергали очистке по способу [6].

Арабиногалактан (AG) использовали неочищенный от примеси 2,7% таннина [7].

Синтез препарата (Cis - AG) проводили по следующей методике.

К 1 г арабиногалактана добавляли 0,08 г цис-дихлородиамминплатины(II) и растворяли в 30 мл воды. Доводили раствор до рН 7 раствором щелочи $\mathrm{NaOH}$ и перемешивали в течение 1 ч. Затем добавляли 30 мл спирта для высаживания осадка. Полученный осадок отфильтровывали и сушили при комнатной температуре. Количество выделенного препарата составило 0,92 г, то есть 85 \% от теоретического. Содержание платины в препарате равнялось 2,6 \%. Анализ на платину проводили весовым методом.

Приготовление продуктов взаимодействия препарата с аптамерами AS9 и AS42:

Аптамеры AS-9 (СTCCTCTGACTGTAACCACGACTGAGCTTTGGTGGGTCGAGCTATG TGCTGCCTCTTCACGCATAGGTAGTCCAGAAGCC) и AS-42 (CTCCTCGACTGTAACCACGT CAATGGGTGATATATGCAGGTTACGCTGGCTAGTTGAAAGCATAGGTAGTCCAGAAGCC) [8] предварительно нагревали при $95^{\circ} \mathrm{C}$ в течение 10 мин и охлаждали на льду в течение 10 мин для восстановления конформации. Продукты Cis-AG-AS9 и Cis-AG-As42 получали смешиванием 200 мкл 200 нм AS9 и 200 мкл 200нм AS42 с 200 мклCis-AG (2 мг/мл) (каждый компонент был разбавлен бесцветным сбалансированным раствором Хэнка, фосфатно-солевым буфером (PBS) или средой DMEM) и инкубировали в течение 25-30 мин при комнатной температуре.

Противоопухолевую активность препарата и продуктов изучали на модели асцитной карциномы Эрлиха и метастатической модели асцитной карциномы Эрлиха. Общее количество клеток у каждого испытуемого животного рассчитывали по общему объему асцитных клеток в асцитической жидкости.

Метастазы получали введением в хвостовую вену мышей 1 млн асцитных клеток в 100 мкл фосфатного буфера. Терапию начинали на 5-е сутки развития опухоли. По окончании лечения мышей вскрывали и определяли количество метастатических очагов и их массу.

$$
-83-
$$


Содержание платины в препарате определяли путем сжигания в муфеле до $1200^{\circ} \mathrm{C}$ в платиновых тиглях. Навеска составляла 160 мг. По разности содержания платины между остатком после сжигания препарата и остатком после сжигания арабиногалактана определяли платину.

Порошковые рентгенограммы регистрировали на дифрактометре X pertPro (PANanalitical, Нидерланды) с геометрией по Бреггу-Брентано, оснащенном полупроводниковым детектором PIXel с графитовым монохроматором. Использовали $\mathrm{CuK \alpha} \alpha$-излучение. Интервал съемки от 10 до 900 с шагом 0,0260 .

Термограммы образцов получали на приборе NETZSCHSTA 449 C с масс-спектральным анализатором отходящих газов QMS403 С в потоке смеси 20 \% O2 -Ar. Нагревание проводили в интервале температур от 20 до $1000^{\circ} \mathrm{C}$ со скоростью $10^{\circ} \mathrm{C}$ в минуту.

ИК-спектры образцов регистрировали на ИК-Фурье спектрометре IRTracer- 100 (Shimadzu, Япония) в области 4000-400 см-1.

\section{Результаты и обсуждение}

Арабиногалактан содержит в качестве примеси 2,7 \% таннина. Ни экстракцией, ни переосаждением полностью удалить его невозможно. Данный результат указывает на способность арабиногалактана образовывать межмолекулярные комплексы [7]. Можно предположить, что при синтезе препарата (Cis-AG) цис-дихлородиамминплатины(II) (Cis) реагирует с COOгруппами, находящимися в таннине, связанном с арабиногалактаном с замещением хлор иона в комплексе с образованием препарата. При обработке препарата 0,5 M HCI мы должны были получить смесь цис-дихлородиамминплатины(II) с арабиногалактаном.

Проведенные физико-химические исследования показали правильность наших предположений. На рис. 1 приведены рентгенограммы исходного препарата (1) и продукта взаимодействия его с $0,5 \mathrm{M}$ раствором $\mathrm{HCl}$ (2). Рентгенограмма (1) отличается от рентгенограммы (2), представ-

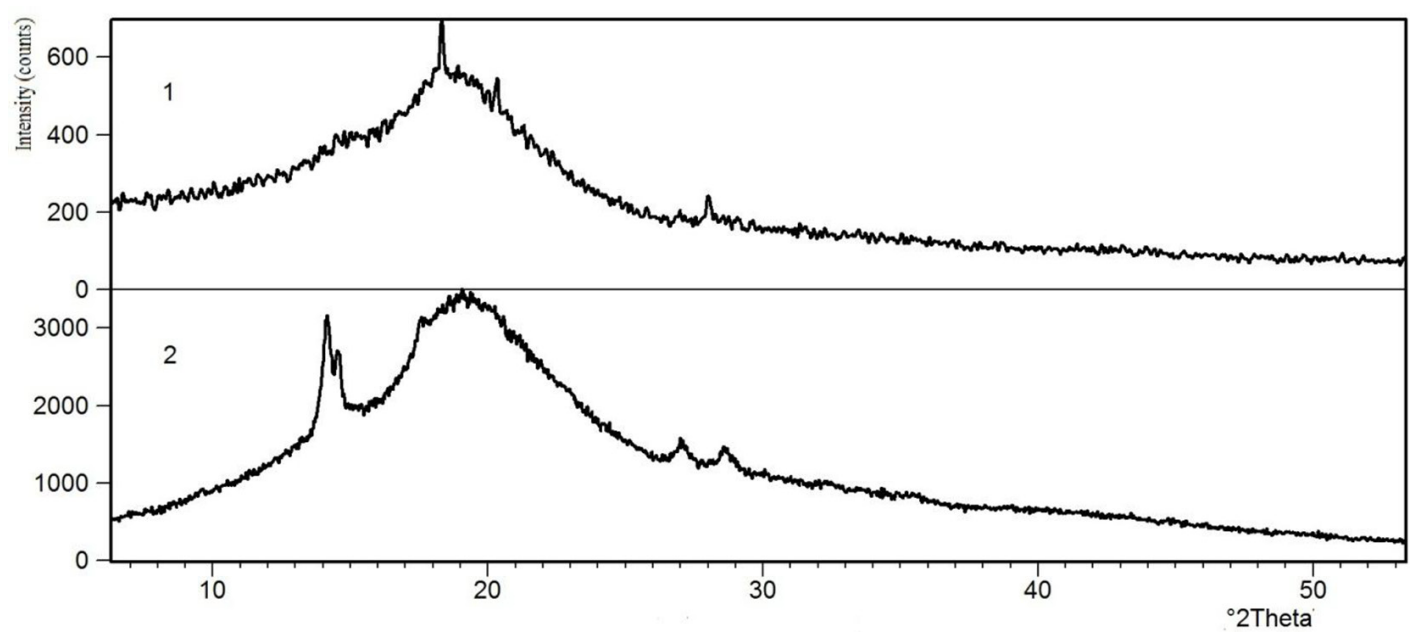

Рис. 1. Рентгенограммы: 1 - препарат, полученный при взаимодействии цис-дихлородиамминплатины(II) с арабиногалактаном; 2 - продукт, полученный при взаимодействии препарата с $0,5 \mathrm{M} \mathrm{HCl}$

Fig. 1. Radiographs: 1 - a drug obtained by the interaction of cis-dichlorodiamminplatin(II) with arabinogalactan; 2 - the product obtained by the interaction of the drug with $0.5 \mathrm{M} \mathrm{HCl}$ 
ляющей собой смесь цис-дихлородиамминплатины(II) и арабиногалактана. Данный результат позволяет утверждать, что полученный препарат содержит цис-дихлородиамминплатины(II) с арабиногалактаном.

Проведено термогравиметрическое исследование препарата и продукта. Данные представлены на рис. 2 и 3.

На рис. 2 приведена термограмма разложенного при нагревании препарата. Наблюдается два экзоэффекта при температуре 231 и $287^{\circ}$ С. Разложение идет в одну стадию. Эти данные указывают на то, что полученный препарат не является смесью.

На рис. 3 приведена термограмма разложения продукта, полученного при взаимодействии препарата с 0,5 M HCl. Наблюдается три экзоэффекта при температуре 279, 305 и $435^{\circ} \mathrm{C}$, характерные при разложении смеси цис-дихлородиамминплатины(II) и арабиногалактана. Разложение идет ступенчато.

Данные ИК-спектроскопического исследования препарата и продукта, полученного при взаимодействии его в $0,5 \mathrm{M}$ растворе $\mathrm{HCl}$, показали, что в ИК-спектре продукта появилась полоса при $1717 \mathrm{~cm}^{-1}$, которая характерна для валентных колебаний карбоксильных групп $\mathrm{C}=\mathrm{O}$ [9]. Эта полоса присутствует и в арабиногалактане, используемом в синтезе препарата. А так как таннин, связанный с арабиногалактаном, содержит дигалловые кислоты, то эту полосу можно отнести к валентным колебаниям карбоксильных групп $\mathrm{C}=\mathrm{O}$ в таннине. В препарате эта полоса отсутствует, что может указывать на связывание цис-дихлородиамминплатины(II) с дигалловыми кислотами, которые находятся в таннине.

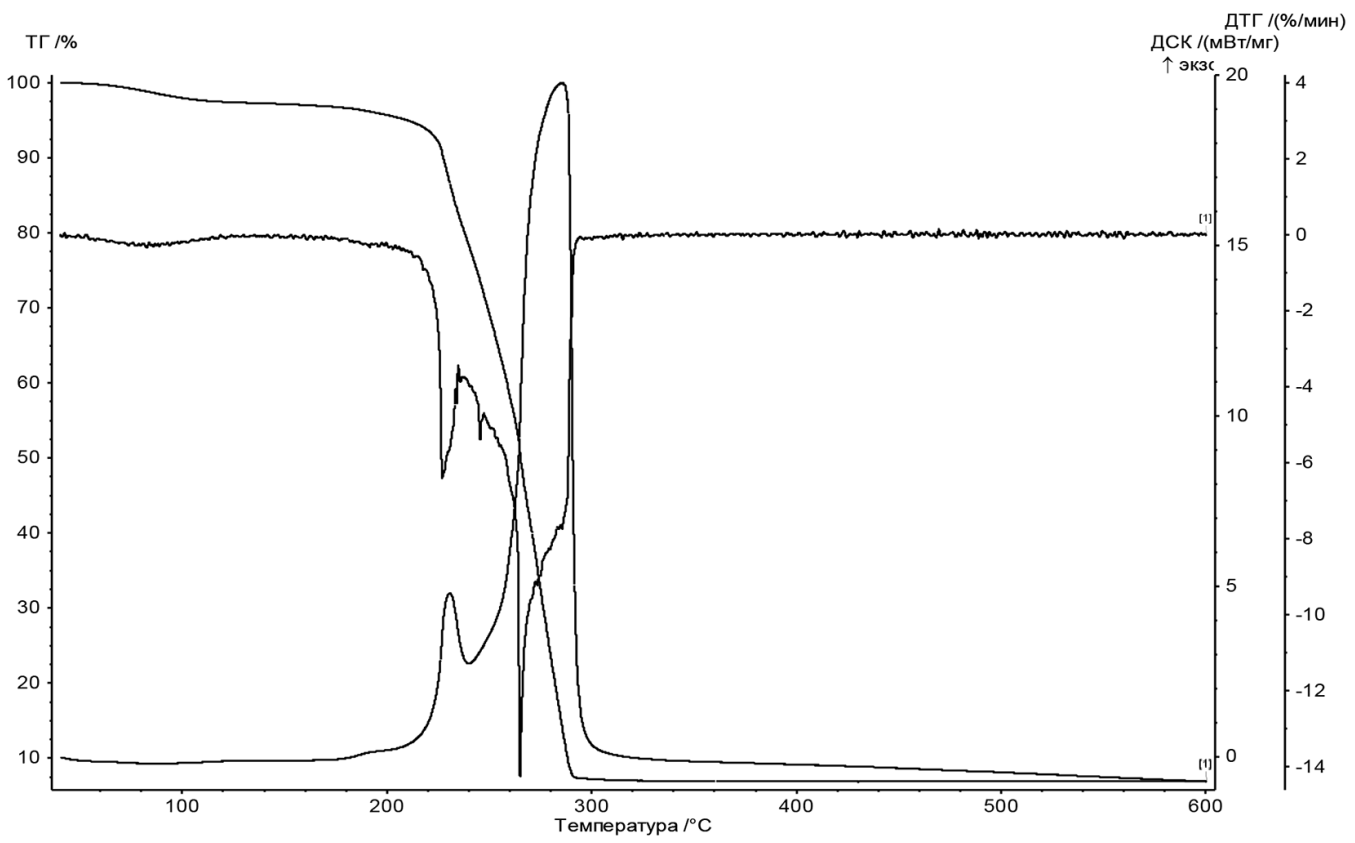

Рис. 2. Термограмма препарата, полученного при взаимодействии цис-дихлородиамминплатины(II) с арабиногалактаном

Fig. 2. Thermogram of the drug obtained by the interaction of cis-dichlorodiamminplatinum(II) with arabinogalactan 


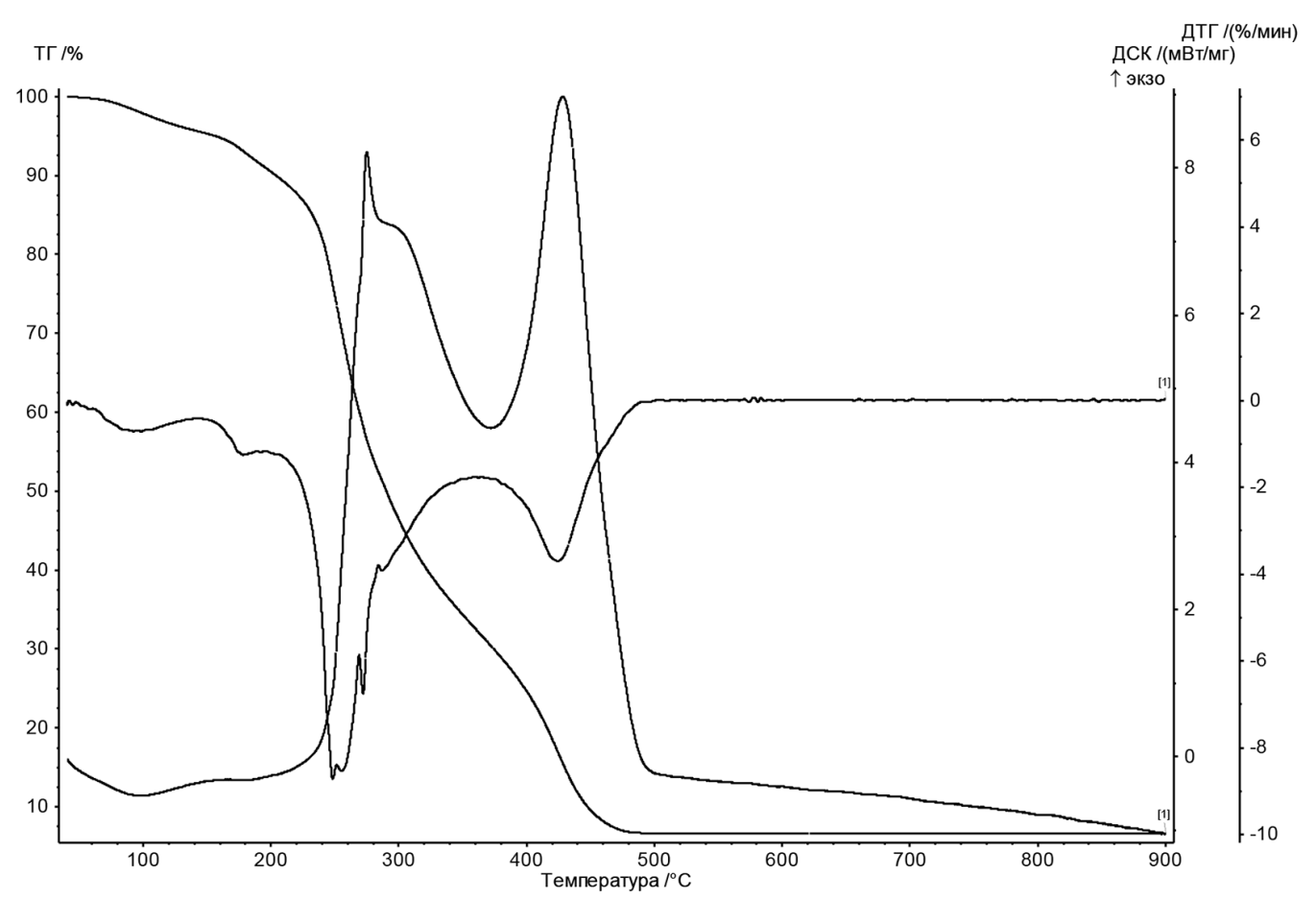

Рис. 3. Термограмма продукта, полученного при взаимодействии препарата в $0,5 \mathrm{M} \mathrm{HCl}$

Fig. 3. Thermogram of the product obtained by the interaction of the drug with $0.5 \mathrm{M} \mathrm{HCl}$

Это указывает на то, что при взаимодействии препарата с 0,5 M HCl происходит отрыв цис-дихлородиамминплатины(II) от таннина, который находится в арабиногалактане.

Полученный препарат был испытан на противоопухолевую активность и влияние его на уровень метастазирования.

Морфологические различия асцитных клеток в опухолях мышей разных экспериментальных групп после двух недель терапии представлены на рис. 4. Асцитные клетки из брюшной полости животных контрольной группы без лечения одинакового размера и имеют округлую форму. В асцитической жидкости мышей, пролеченных комплексами Cis-AG и Cis-AG-AS9, большинство клеток находится в состоянии апоптоза и некроза; кроме того, на мазках наблюдается большое количество апоптотических телец и эритроцитов. Таким образом, препарат в процессе адресной доставки с аптамерами, вызывает апоптоз опухолевых клеток [10], который практически не зависит от типа аптамера.

Было изучено влияние цис-дихлородиамминплатины(II) (Cis), препарата и продукта его доставки с аптамером на уровень метастазирования. В этом эксперименте для адресной доставки препарата использовали аптамер к асцитным клеткам AS42 [8]. Cis, препарат и продукт его доставки с аптамером вводили 8 раз через день. Определяли распределение метастазов и массу опухолевых очагов. Результаты исследований представлены в таблице. Наибольшее количество метастазов (суммарно) выявлено у животных контрольной группы без лечения (всего 24). В основном метастазы были обнаружены в щитовидной железе, тимусе, хвосте, мышцах и легких. Суммарная масса метастазов у 8 животных составила 6,9 г. Минимальное суммарное 


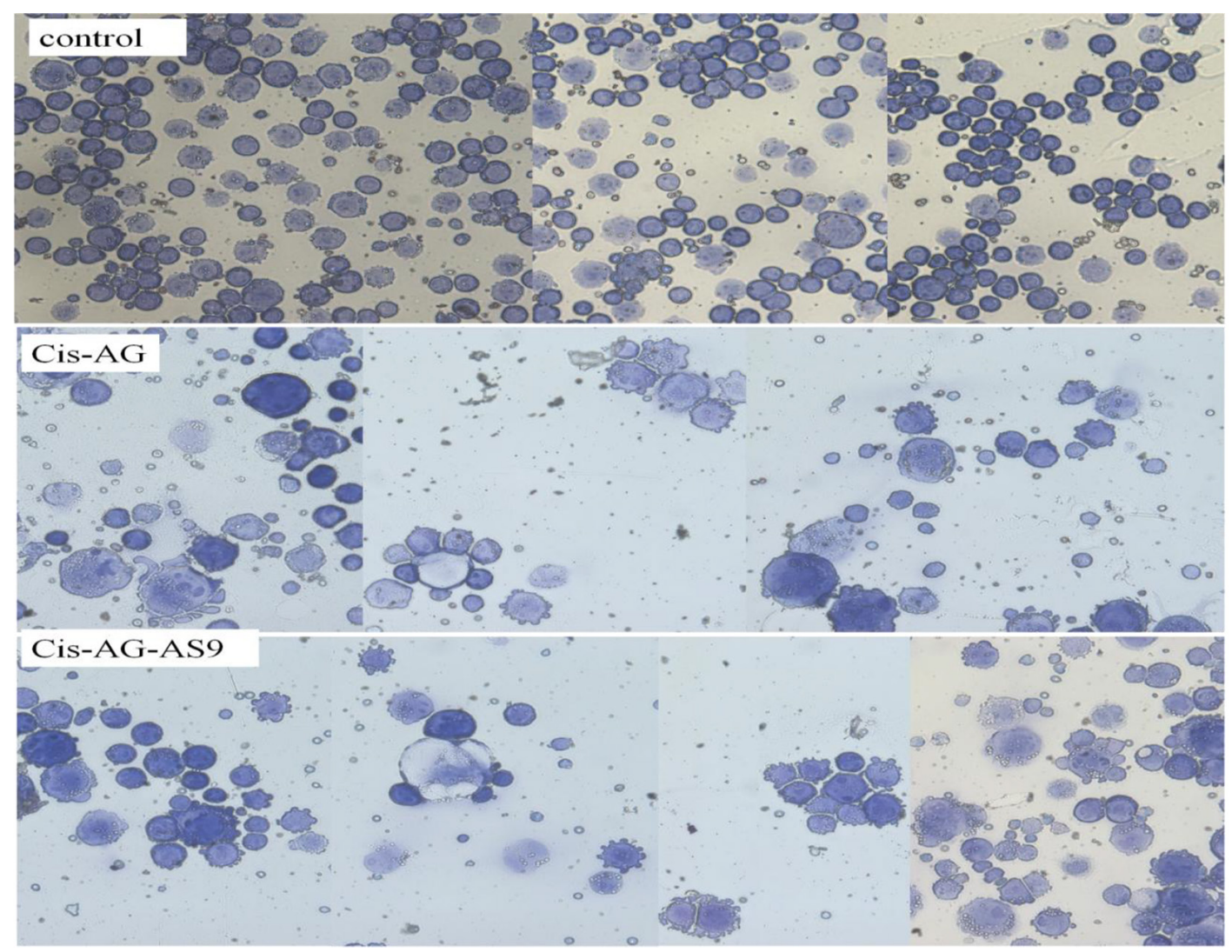

Рис. 4. Мазки интактной асцитической жидкости, выделенной из брюшной полости мышей различных экспериментальных групп, зафиксированных метанолом и окрашенных краской Романовского-Гимза. Magnification 40x

Fig. 4. Smears of intact ascitic fluid isolated from the abdominal cavity of mice of various experimental groups, fixed with methanol and stained with Romanovsky-GIEMS paint. Magnification 40x

количество метастазов и минимальная суммарная масса метастазов наблюдались у животных из групп, которых лечили Cis, препаратом, с его адресной доставкой аптамером AS42 (Cis-AGAS42). Количество метастазов у мышей этих групп (Сis и Cis-AG-AS42) было меньше в 3 раза, а суммарная масса метастазов - в 5,6 раза и 4,7 раза соответственно (таблица). Таким образом, в целом препарат и продукт его доставки с аптамером, несмотря на низкую долю в них Сis, обладали сопоставимой с цис-дихлородиамминплатиной(II) способностью подавлять рост метастазов. Причем концентрация платины в препарате в 25 раз ниже, чем концентрация платины в цис-платине, что существенно снижает его токсичность.

\section{Заключение}

Получен новый препарат на основе цис-дихлородиамминплатины(II), арабиногалактана и аптамераAS-42, проявляющий противоопухолевую активность на карциноме Эрлиха, сравнимую с активностью цис-платина, но существенно уменьшающую концентрацию платины в препарате (более чем в 25 раз). Это позволяет снизить его токсичность при химиотерапии. Комплексное исследование свойств препарата методами РФА, СТА и ИК-спектроскопии позво- 
Таблица. Распределение метастазов у мышей при терапии цис-платином, препаратом и продуктом взаимодействия препарата с аптамером

Table Distribution of metastases in mice during therapy with cis-platinum, the drug and the product of interaction of the drug with aptamer

\begin{tabular}{|c|c|c|c|c|c|c|c|c|c|c|c|c|c|c|c|c|c|}
\hline \multirow[t]{2}{*}{ № } & Группы & \multicolumn{14}{|c|}{ Распределение метастазов } & \multirow{2}{*}{ Всего } & \multirow{2}{*}{ Macca, г } \\
\hline & & a & $\mathrm{b}$ & $\mathrm{c}$ & $\mathrm{d}$ & e & f & g & $\mathrm{h}$ & $\mathrm{i}$ & $\mathrm{j}$ & $\mathrm{k}$ & 1 & $\mathrm{n}$ & $\mathrm{n}$ & & \\
\hline 1 & Control & 3 & 5 & 4 & 3 & 1 & 1 & 4 & 1 & 1 & 1 & - & - & & - & 24 & 6,9 \\
\hline 2 & Cis & 2 & 1 & - & - & - & - & 1 & - & & - & 3 & - & & 1 & 8 & 1,24 \\
\hline 3 & $\mathrm{Cis}+\mathrm{AG}$ & 1 & 3 & 3 & 1 & 2 & - & - & - & 1 & 1 & 1 & 2 & t & - & 16 & 1,85 \\
\hline 4 & $\mathrm{Cis}+\mathrm{AG}+\mathrm{AS} 42$ & 1 & 1 & 3 & 1 & - & - & 1 & - & 2 & - & - & 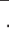 & . & - & 9 & 1,51 \\
\hline
\end{tabular}

Примечание: $\mathrm{a}$ - щитовидная железа, b - тимус, c-хвост, d - мышцы, e - сердце, f - желудок, $\mathrm{g}$-легкие, $\mathrm{h}$ - aсцит, $\mathrm{i}$ - спина, j - нога, $\mathrm{k}$ - кишечник, 1 - горло, $\mathrm{m}$ - мочевой пузырь, $\mathrm{n}$ - грудина.

ляет сделать заключение о том, что арабиногалактан связан с цис-дихлородиамминплатины(II) за счет примеси таннина в нем.

\section{Список литературы / References}

1. Патент РФ № 2566290. Старков А.К., Кожуховская Г. А., Павленко Н.И. Способ получения препарата на основе взаимодействия цис-дихлородиамминплатины(II) с арабиногалактаном. Опубл. 20.10.2015. Бюл. № 29. [Patent 2566290 RU Starkov A. K., Kozuchovskaya G. A., Pavlenko N.I. A methodof producing drag based on interaction cis-dichlorodiamine platinum with arabinogalactan. Publ. Date 20.10.2015 (In Russ.)]

2. Старков А.К., Кожуховская Г.А., Павленко Н.И. Получение и идентификация продукта взаимодействия соли цис-дихлородиамминплатины(II) с арабиногалактаном и его терапевтическое действие. Координационная химия. 2014. Т. 40(9). С. 575-576. [Starkov А.К., Kozuchovskaya G. A., Pavlenko N. I. Obttaining and identification the product of the interaction of the cis-dichlorodiamine platinum solt with arabinogalactan and its therapeutic effect. Russian Journal of Coordination Chemistry. 2014. V. 40(9). P. 575-576. (In Russ.)]

3. Старков А.К., Замай Т.Н., Савченко А. А., Инжеваткин Е. В., Титова Н. М., Силкин П.П., Коловская О.С., Лузан Н.А., Кузнецова С.А. Противоопухолевый эффект комплекса арабиногалактана с платиной. Доклады Академии наук 2016. Т. 467. № 1. С. 112-114. [Starkov A. К., Zamay T.N., Savchenko A.A., Inzhevatkin E.V., Titova N.M., Silkin P.P., Kolovskaya O.S., Lusan N.A., Kuznecova S.A. The Antitumor effect of complex arabinogalactan with platinum. Russian Journal Doklady Akademii Nauk. 2016. Vol. 467(1). P. 112-114. (In Russ.)]

4. Малков Ю.А., Медведева Е.Н., Бабкин В.А. Усовершенствованная технология производства высокочистого арабиногалактана. Химия растительного сырья. 2018. № 2. С. $183-$ 189. [Malkov Yu.A., Medvedeva E. N., Babkin V.A. Improved production technology of high-purity arabinogalactan. Chemistry of plant raw materials. 2018. № 2. P. 183-189. (In Russ.)]

5. А.c. СССР № 1445144 Старков А.К., Кирик С.Д., Казбанов В.И. Бис-( тетраамминплатина(II) как промежуточный продукт в синтезе цис-платина и способ ее получения. Опубл. 08.04.1986. [Copyright certificate of the USSR1445144. Starkov A.K., Kirik S.D., 
Kazbanov V.I. Bis- ( $\mu$-oxalato) tetraamminplatinum (II) as an intermediate in the synthesis of cisplatin and the process for its preoaration. Publ. Date 08.04.1986. (In Russ.)]

6. А.с. СССР № 1640920. Старков А. К., Казбанов В. И., Карпова Н. В., Борисов В. В., Малиновская Л.М. Способ очистки цис-дихлородиамминплатины(II). Опубл. 20.02.1989. [Copyright certificate of The USSR1640920. Starkov A.K., Kazbanov V.I., Karpova N.V., Borisov V.V., Malinovskaya L. M. A method for purifying cis-diaminedichloroplatinum (II), Publ. Date 20.02.1989. (In Russ.)].

7. Медведева Е.Н., Остроухова Л.А., Неверова Н.А., Онучина Н.А., Бабкин В.А. Фенольные примеси в арабиногалактане из древесины лиственницы. Химия растительного сырья. 2011. № 1. C. 45-48. [Medvedeva E. N., Ostrouchova L.A.. Neverova N.A., Onuchina N. A., Babkin V.A. Phenolic impurities in arabinogalactan from larch wood. Chemistry of plant raw materials. 2011. № 1. P. 45-48. (In Russ.)]

8. Kolovskaya O.S., Zamay T.N., Zamay A.S., Glazirin Yu.E., Spivak E.A., Zubkova O.A., Kadkina A.V., $\quad$ Erkaev E.N., Zamay G. S., $\quad$ Savitskaya A.G., Trufanova L. V., $\quad$ Petrova L.L., Berezovsky M. V. DNA - aptamer/protein interaction as a caurse of apoptosis and arrest of proliferation in Erlich ascites adenocarcinoma cells. Biochemistry Moscow-Supplement Series Biomedical Chemistry. 2014. Vol. 8(1). P. 60-72.

9. Nakamoto K. Infrared and Raman Spektre of Inorganic and CoordinationnCompounds. New York: Third Edition. 1978. Р. 233-238.

10. Замай Т.Н., Старков А.К., Коловская О.С., К Кичкайло А.С. Инжеваткин Е.В., Замай Г.С., Титова Н.М., Замай С.С, Пац Ю.С. Снижение токсичности цис-платина путем его конъюгации с арабиногалактаном. Биологические мембраны 2020. T. 37(1). С. 1-7. [Zamay T. N., Starkov A.K., Kolovskaya O.S., Kichkailo A.S., Inzhevatkin E.V., Zamay G.S., Titova N.M., Zamay S. S., Patc Y.S. Reduction of the Cysplatin Toxicity by its Conjugation with Arabinogalactan. Biochemistry (Moscow) Suplement. Series A: Membrane and Cell Biology. 2020. Vol. 14(1). P. 61-66. (In Russ.)] 